\title{
Avoiding plagiarism using Mendeley in Indonesian higher education setting
}

\author{
Andi Anto Patak, Muhammad Tahir \\ English Department, Faculty of Languages and Literature, Universitas Negeri Makassar, Indonesia
}

\begin{tabular}{l}
\hline \hline Article Info \\
\hline Article history: \\
Received Aug 1, 2019 \\
Revised Oct 12, 2019 \\
Accepted Nov 24, 2019 \\
\hline
\end{tabular}

\section{Keywords:}

Academic honesty

Avoid plagiarism

Citation and reference

Higher education

Mendeley

\begin{abstract}
People who plagiarize have a complex problem. Plagiarism could be by accident, by mistake, or on purpose. This research aims at exploring the reasons for plagiarizing and the significance of citing and referencing using Mendeley to avoid plagiarism. Four Indonesian Mendeley Advisors were interviewed online using convenient sampling technique. This study revealed that reasons for plagiarizing are time restriction, laziness, and busy. The significance of citing and referencing using Mendeley to avoid plagiarism are (1) confirm, justify, and claim the issue conveyed in scientific work; (2) highlight a particular idea; (3) criticize or approve the premise of others, and (4) build argument. Mendeley usage acquaintance for scientific writing is expected to be practical tools for avoiding plagiarism and promote academic honesty in the setting of higher education. However, the role of supervisor is crucial to provide useful feedback for their students' writing to help students avoid plagiarism. Besides, university should create comfortable academic environment by providing free seminar and workshop on academic writing to educate students avoid plagiarism.
\end{abstract}

Copyright (c) 2019 Institute of Advanced Engineering and Science. All rights reserved.

\section{Corresponding Author:}

Andi Anto Patak, English Department, Faculty of Languages and Literature, Universitas Negeri Makassar, Makassar, 90221, Indonesia.

Email: andiantopatak@unm.ac.id

\section{INTRODUCTION}

The IEEE distinguishes plagiarism into several levels started from the hardest cases [1]. Firstly, cutand-paste from a paper without mentioning the source, included in this category if plagiarism is done more than $50 \%$ of the original text. In this category, many parts of the original paper are copied without reference at all. Secondly, copy a large portion from twenty percent to fifty percent without mentioning the source. Thirdly, copy some writing elements, such as paragraph, sentence, picture, or table without saying the sources. Fourthly, rewrite a page or paragraph without citing the original reference; some words or sentences can be changed in order, but without saying the source, it is still called plagiarism. Lastly, if the copied text has mentioned the source, the method of disclosure is incorrect, for example, locating quotes in sentences whose original text is not changed, or copy sentences that change the order or only replace some words.

Plagiarism is the recognition of the work of others by someone who makes the work as his work [2], [3]. People who do plagiarism are called plagiarists, with such restrictions; plagiarism is theft (piracy), and plagiarists are a thief (hijacker). The Random House Compact Unabridged Dictionary [4] defines plagiarism as "the use or imitation of the language and thought of other writers and their representation as someone's original work." Many academics also consider this as a violation of scientific ethics and intellectual property. In writing scientific work, it is indeed inseparable from the quotations of ideas, ideas, and theories of others who have been published to support the opinions that we have built-in writing. The quotation cannot be carried out at will; there are ethics and guidelines in including other people's ideas and theories in a 
scientific paper that we compile. This needs to be done to avoid academic fraud in the form of plagiarism that often occurs.

Plagiarism is taking essays of others and making it as if our article, for example publishing other people's writings on our behalf. Therefore, it is essential to understand the citation guidelines as a form of respecting the results of other people's thoughts; hence, it is subject to avoid plagiarism. Referring other people's words or sentences without mentioning the identity of the sources or without using quotation marks is categorized as plagiarism [5]. Using other people's ideas, views, or theories without specifying the identity of the source and using other people's facts (data, information) without saying the source's identity also comprise the plagiarism. Recognizing other people's writing or paraphrasing (changing the sentence of another person without changing the idea) without mentioning the identity of the source, indeed a category of plagiarism [6]. Submit scientific works produced and published by another party as if they are our works are plagiarism as well [7]. The complexity of citation leads this study focusing on proper citation and references in academic writing to avoid plagiarism.

Therefore, it is crucial to understand how to include other people's ideas and theories to compose a good scientific paper. As for avoiding plagiarism, at least an effort is required to learn the writing techniques with right quotation. In scientific work writing, the authors use other authors' ideas and theories as the quotation to support the arguments. Quotes can be made from print, online, audio, or from audiovisual in the form of video or radio. How to quote in writing can be done through direct quotes and indirect quotes. Meanwhile, long sentences in the quotation that are not relevant to the writing theme should be taken into account to avoid. When someone uses ideas, information, even opinions that are not their thoughts, the citation is a must $[8,9]$. This also applies even though the author does not use the same words. The author must provide a source of information. The source is for not only books, journals, theses, or audio/visual recordings, but also citations for ideas from the internet must be included.

Stating the copyright holder of the ideas, theories, and opinions in the text are varied based on the citation and reference style, such as writing the last name and year of the publication, as well as the page number. If the citation comes from website, it can be done by stating the name of the author/institution if there is one, accompanied by a complete address (link) from the source in references [10]. The references is compulsory when paper writing. However, some conventional way of scientific writing still registering the literature manually after the writing is finished [11-13]. This is not wrong, but it has the potential to skip one, two, or several sources [5]. In a sense, the sources are listed in the citation-in-text but are missed in the references. In scientific writing, such a thesis, dissertation, journal article, and book, it is critical to list all the sources in references to avoid plagiarism [14]. Besides, the inconsistency between citation and references and vice versa makes a hassle if there is a change on citation style; it would take time to synchronize. By synchronizing between citation-in-text and references from the beginning, errors can be minimized. The technical is more or less the same as a direct citation-in-text; the sources in references are written in more details, including the name of the author, the year of writing, the title of the paper, the publisher and the publishing location [8].

The citation and references are parts of a legitimate and essential process in scientific writing. In an academic context, deliberate action of a writer or researcher to use the work, ideas, or expression of others as if they are their work is categorized as plagiarism [14-19]. In all aspects of academic research, positive thoughts and ideas are built based on the ideas from other authors or researchers. However, the technique of citation must be done correctly. University has a firm vision for student found deliberately copying or plagiarizing the work of others is undoubtedly banned [20]. Thesis writing manuals should include a university policy statement concerning academic honesty [21]. Deliberate plagiarism with a clear intention to deceive, however, is far less common than plagiarism committed through misunderstanding or even carelessness $[18,19]$. This latter type of plagiarism may occur if the author is unsuccessful to recognize the sources of knowledge and ideas in her/his scientific work after combining ideas or facts taken from other authors.

By using the principle of presumption of innocence, not entirely the case of plagiarism is based on malicious intent and dishonest will. There is also plagiarism due to the ignorance of how to cite and use the source of the writing $[16,22]$. In avoiding the act of plagiarism, a writer must honestly include other people's ideas [14]. The author should also honestly cite the theories and previous findings or research results of others to the visible history of research. Any author should consider that even experts also cite other sources. A professional writer cites the findings, opinions, and the work of others accurately and honestly from a valid source according to the ethics and rules of writing [14]. For example, a writer wants to find ideas to create a proper draft; then, it is necessary to find ideas or opinions from practitioners and or experts with proper acknowledgement. The author is often less precise in citing and referencing sources manually. However, the words or editorial sentences of the expert must be appropriately referenced and distinguished from our own words [17]. 
Nowadays, many applications could help to create synchronizing between citation and reference, such as Mendeley [13, 23-25]. The Mendeley application is subject to ease listing the references automatically based on the citation-in-the text. Mendeley provides a virtual space free of 2 GB to manage the collection of sources as personal library. Mendeley also provides a plugin for a word processor. Mendeley with Microsoft Word Plugin became the most loyal software for scientific writers. This program is equipped with the feature to synchronize citations-in-text and references. By using Mendeley, reference and preparation of references are effortless and light. Search and library storage can be done automatically from the internet to find related sources to cite. In addition, citations are included to avoid acts of academic theft or plagiarism. This study aims at exploring reasons for plagiarizing and the significance of citing and referencing using Mendeley.

\section{METHOD}

Four Mendeley Advisors who are members of the Indonesian Mendeley Community were subject of this study. They were purposively chosen to be interviewed online using convenient sampling technique $[26,27]$. The chosen research subjects meet the criteria of active Mendeley Advisors that spread the use of Mendeley in academic writing. The interview protocol is design to explore reasons for plagiarizing and the significance of citing and referencing using Mendeley to help scholars avoiding plagiarism. We used NVivo 8 software to transcribe and translate the recorded interview results using a thematic analysis. The thematic analysis is a part of a qualitative research method. This analysis is prevalent to explore the response of research subject or interviewee [28, 29]. Thematic analysis directs the research to highlight the theme and subtheme in the transcript. We coded the interviewee and themes on the transcripts for a confidential reason.

\section{RESULTS AND DISCUSSION}

In writing scientific papers for publications in proceedings, books, or journals, the accuracy of citation style is needed. Citation encompasses the quotation of sources from previous research or scientific works that have been published as a reference for our writing. This is done to avoid acts of plagiarism; hence, we need a tool in the form of software that could help adequately cite based on the correct and accurate sources. This research reported the themes and sub-themes appeared based on the interview concerning avoiding plagiarism using Mendeley. The Indonesian Mendeley Advisors as the interviewee or research subject revealed two themes in the interview. Mendeley Advisors reported that there are three reasons people engaged in plagiarism; the reasons are: time restriction, laziness, busy.

The second theme is the significance of citing and referencing, which include four sub-themes: Confirm, justify, and claim the issue conveyed in scientific work; Highlight a particular idea; Criticize or approve the premise of others; Build an argument.

\subsection{Reasons for plagiarizing}

This study explores the various reasons that underlie scholars to plagiarize, as revealed by Indonesian Mendeley Advisors. Based on the experience of the Indonesian Mendeley Advisor, they found that some reasons make academicians involved in plagiarism. The Indonesian Mendeley Advisors reported that people who engaged in plagiarism due to the laziness, time restriction, busy in producing scientific work. It seems that Mendeley Advisor considered plagiarism is publishing the work of others either to some extent or from top to bottom without proper credits. There are many cases of plagiarism that have been revealed, and the effect, of course, against the credibility of an author [22]. The first theme reported by Mendeley Advisor in this study is the reasons for plagiarizing, including three sub-themes as follows:

\subsubsection{Time restriction}

Mendeley Advisors stated that people engaged in plagiarism due to time restriction. Limited time working on tasks or too many tasks that must be completed at the same time could tempt people to plagiarize. Often the perpetrators of plagiarism are pressed for time, for example, students who are threatened with Drop Out because the study period is running out. Students might plagiarize because lecturers only provide a deadline of a few days to collect assignments and journal deadlines that must be published immediately. Due to limited time, the student must think about the easiest way to achieve results before the deadline. The easiest and most likely way is to cut and paste other works. Often students are assigned to accomplish writing in a short time affected them to look for shortcuts way by copying articles that were scattered on the internet with a little 'polish' so that it resembled as if her/his own works. 


\subsubsection{Laziness}

After interviewing the Mendeley Advisor, this study revealed that laziness is one of the reasons people involved in plagiarism. As we have seen, an article is an idea in written form so that others can read it. In other words, the writing becomes a medium for transferring ideas from the writer to the reader. However, sometimes when dealing with writing assignments, people are often unable to come up with new ideas. Even worse, they are lazy to think. This is what triggers the copying of other people's works. This technique is considered the fastest and practical way to solve problems without considering the risks. Lazy reading is the main factor causing a person to do plagiarism because this is related to how much knowledge one has, whereas writing is a process of transferring knowledge and ideas. Someone who is lazy to read certainly does not have enough ideas or new ideas that can be developed in written form.

\subsubsection{Busy}

Mendeley Advisors described that plagiarism cases are quite often found in master and doctorate students who are work and have children. The increasingly long-tailed plagiarism - mostly done by academics - shows the fragility of the intellectual building of higher education. Higher education should be responsible for producing a scholar who has academic integrity to be an example of people behavior against moral destruction in writing. Universities also have bureaucracy in general; lecturers or supervisors are busy with formal routines, but they are expected to have quick responses to socio-cultural and technological changes outside academic environment. Mendeley Advisors also told that supervisors are busy so that they could not provide adequate supervision for their students. Students seem to experience less feedback on their writing assignment.

\subsection{The significance of citing and referencing}

This theme is subject to the significance of citing and referencing to avoid plagiarism. The Indonesian Mendeley Advisors experienced that citing and referencing using Mendeley seems to be considerable for Indonesian scholars to avoid plagiarism. The Indonesian Mendeley advisors reported that the cited source is indispensable in supporting the idea of the writer that someone else has previously conveyed a similar idea. Mendeley Advisors experienced that an author intends to confirm and justify the issue conveyed by using Mendeley to cite sources. Mendeley Advisors also reported that a writer could highlight a particular idea as a new issue in knowledge development. Citation process using Mendeley is also considered substantial by Mendeley Advisors to criticize or approve the premise of others. It is also reported by Mendeley Advisors that academicians are expected to contribute to the research and development of knowledge by sharing their ideas, evaluations, and arguments. The sub-themes of the significance of citing and referencing are as follows:

\subsubsection{Confirm, justify, and claim the issue conveyed in scientific work}

The Indonesian Mendeley advisors reported that the cited source is indispensable in supporting the idea of the writer that someone else has previously conveyed a similar idea. Citation to similar idea using Mendeley makes an author intends to confirm and justify the issue conveyed. Acknowledge every previous similar idea in the form of printed, oral, or electronic information is very important; otherwise, we will be accused of plagiarism [8]. Citing and referencing which encompasses the form of confirming and justifying the issue conveyed by other authors using Mendeley is intended to avoid plagiarism [30] and show the number of reading sources as a reflection of the research quality [31]. Strengthening the confirmation and justification of published issues required synchronization between citations and references. It could guarantee to explain the origin or history of the information and indicate how new or updated the information is [10]. Therefore, the author should confirm that all the citations in the text are also in the list of references. Any sources contained in the references should be listed in a specific citation format or style. Understanding how to use appropriately and acknowledge the contributions of other authors to our scientific work is an essential step in scientific writing. When writing scientific papers, confirming all references are listed in full from each source used is leading to justification on the issue conveyed in the writing. This method is intended to ensure that an author has all the information needed.

Ultimately, this study revealed that Mendeley Advisor specified that using Mendeley is helpful to give credits to the work of others and to show strong claims for research results as scientific work. Scientific studies begin by investigating the findings of previous scientists. The scientific work must be written in our language style, but the inclusion of citation and reference to other authors is a sign of gratitude for the source of ideas that inspire to write with appropriate format or style [14]. Even if our work is entirely written in our sentence style, we still have to cite the source of information to give honest appreciation and recognition to the other scientist or researcher and to show the thoroughness of our research. The honest recognition of the contributions of other researchers to the development of knowledge in scientific work is the most compelling 
rationale for strong claim of innovation in scientific setting. In addition, Mendeley Advisor seems to believe that Mendeley users could be indisputable to claim actively that the research results have novelty due to the precise history of all the related sources are included.

\subsubsection{Highlight a particular idea}

Mendeley Advisors also reported that a writer could highlight a particular idea as a new issue in knowledge development or challenging topic to discuss further. The advisors' report implied that when a writer or an author is writing the exact words, it is necessary to highlight the appropriate citation, and add notes about the particular page relevant to the reference details. This technique is subject to ensure that when to note, we can distinguish between our own words and from the sources we cite [18]. Highlighting particular idea in Mendeley could ease an author to follow the rules and ethics in quoting sentence or statement. Highlight also function to assure an author in mentioning the cited sources. Eventually, an author could provide complete information about the sources. The highlight also comprises an appreciation or respect to particular sources. Highlight also includes a reflection of integrity, honesty, and openness to develop a particular idea from other authors.

\subsubsection{Criticize or approve the premise of others}

Citation process using Mendeley is also considered substantial by Mendeley Advisors to criticize or approve the premise of others. Using Mendeley citation and reference manager is an essential step of a scholar's proficiency to read a discipline extensively and to integrate the ideas and research of others into scientific work. A writer of a scientific paper should also use evidence from the literature to support the research conclusions to ensure the reader knows where the information or evidence was obtained [32-35]. Thus, by citing ideas, research data, evidence, and conclusions of others appropriately, the reader can criticize or even approve the difference between the previous findings and the current scientific work being read or written. Of course, an author is required to integrate previous research and make it easier to track sources that help in criticize or approve the other premises.

\subsubsection{Build argument}

Mendeley Advisors argued that Mendeley enables the task of a scholar to learn new things and contribute to the development of argument. Scholars build argument through careful research and broaden the ideas of others [36]. Academicians are expected to contribute to the research and development of argument by sharing their ideas. Lecturers do not require students to write the paper entirely but expect the students to produce to the original idea to create space for building the argument. It aims to create and express ideas in scientific work, acknowledge all sources, complete tasks independently or in collaboration, and construct accurate research reports. Every author is responsible to provide reference sources using appropriate citation styles. Referring appropriately to a source leads the readers finding the source and understanding the argument. Identifying resources help us following the argument and avoid plagiarism by linking other people's contributions to our scientific work. Plagiarism happens if an author uses the scientific work of others to gain credits or profit without formally acknowledging that the scientific work is contributed by another work $[15,17]$.

\section{CONCLUSION}

Mendeley Advisor interviewed in this study reported their perception of reasons for plagiarizing and the significance of citing and referencing using Mendeley for avoiding plagiarism in Indonesian higher education setting. Mendeley advisors identified three reasons for plagiarizing; they are time restriction, laziness, and busy. Based on the interview in this study, Mendeley Advisors exposed that the significance of citing and referencing using Mendeley to avoid plagiarism consists of four aspects. Firstly, confirm, justify, and claim the issue conveyed in scientific work. Secondly, highlight a particular idea. Thirdly, criticize or approve the premise of others. Fourthly, build argument. The use of Mendeley in scientific writing is projected to be effective tools for plagiarism deterrent and academic honesty promotion in the Indonesian higher education setting. However, the supervisor's role is vital to be responsible for effective feedback on students' writing to assist students evade plagiarism. In addition, university should support the academic atmosphere in case of open and free seminar and workshop for students concerning academic writing to train students avoid plagiarism.

Int. J. Eval. \& Res. Educ. Vol. 8, No. 4, December 2019: 686 - 692 


\section{ACKNOWLEDGEMENTS}

Directorate of Research and Community Service, Directorate General of Research Empowerment in the Ministry of Research, Technology, and Higher Education of the Republic of Indonesia grants this study by contract number:1836/UN36.9/PL/2017.

\section{REFERENCES}

[1] IEEE, "Identifying Plagiarism," 2019. [Online]. Available: https://www.ieee.org/publications/rights/plagiarism/idplagiarism.html.

[2] J. Debnath, "Plagiarism: A silent epidemic in scientific writing-Reasons, recognition and remedies," Med. J. armed forces india, vol. 72(2), pp. 164-167, 2016.

[3] G. Helgesson and S. Eriksson, "Plagiarism in research," Med. Heal. Care Philos., vol. 18(1), pp. 91-101, 2015.

[4] S. B. Flexner, Random House Compact Unabridged Dictionary. Random House, 1996.

[5] R. A. Harris, Using sources effectively: Strengthening your writing and avoiding plagiarism. Routledge, 2017.

[6] S. E. Nancekivell, O. Friedman, and S. A. Gelman, "Ownership matters: People possess a naive theory of ownership," Trends Cogn. Sci., 2018.

[7] S. F. M. Razali, A. Mutalib, N. Hamzah, and S. Baharom, "Plagiarism among first year university students using autocad assignments," Pertanika J. Soc. Sci. Humanit., vol. 24, pp. 25-34, Apr 2016.

[8] R. Pears and G. J. Shields, Cite them right: the essential referencing guide. Palgrave Macmillan, 2016.

[9] C. Lipson, Doing honest work in college: How to prepare citations, avoid plagiarism, and achieve real academic success. University of Chicago Press, 2019.

[10] K. Williams and M. Davis, Referencing and understanding plagiarism. Macmillan International Higher Education, 2017.

[11] K. Salija, R. Hidayat, and A. A. Patak, "Mendeley impact on scientific writing: Thematic analysis," Int. J. Adv. Sci. Eng. Inf. Technol., vol. 6(5), p. 657, Oct. 2016.

[12] A. A. Patak, H. A. Naim, and R. Hidayat, "Taking mendeley as multimedia-based application in academic writing," Int. J. Adv. Sci. Eng. Inf. Technol., vol. 6(4), pp. 557, Aug. 2016.

[13] H. Zaugg, R. E. West, I. Tateishi, and D. L. Randall, "Mendeley: Creating communities of scholarly inquiry through research collaboration," TechTrends, vol. 55(1), pp. 32-36, Jan. 2011.

[14] M. Roig, "Avoiding plagiarism, self-plagiarism, and other questionable writing practices: A guide to ethical writing." 2006

[15] S. Angélil-Carter, Stolen language?: Plagiarism in writing. Routledge, 2014.

[16] D. Pecorari, "Good and original: Plagiarism and patchwriting in academic second-language writing," J. Second Lang. Writ., vol. 12(4), pp. 317-345, Dec. 2003.

[17] A. Pennycook, "Borrowing others' words: Text, ownership, memory, and plagiarism," Tesol Q., vol. 30(2), pp. 201, Jan. 1996.

[18] W. Sutherland-Smith, Plagiarism, the Internet, and Student Learning: Improving Academic Integrity. Taylor \& Francis, 2008

[19] W. Sutherland-Smith, "Pandora's box: Academic perceptions of student plagiarism in writing," J. English Acad. Purp., vol. 4(1), pp. 83-95, Jan. 2005.

[20] R. M. Howard, "Plagiarisms, authorships, and the academic death penalty," Coll. English, vol. 57(7), pp. 788-806, 1995.

[21] J. E. Mauch and N. Park, Guide to the Successful Thesis and Dissertation: A Handbook for Students and Faculty, Fifth Edit. New York • Basel: Marcel Dekker, Inc., 2003.

[22] M. Devlin and K. Gray, "In their own words: A qualitative study of the reasons Australian university students plagiarize," High. Educ. Res. Dev., vol. 26(2), pp. 181-198, Jun. 2007.

[23] M. Basri and A. A. Patak, "Exploring Indonesian students' perception on mendeley reference management software in academic writing," in 2015 2nd International Conference on Information Technology, Computer, and Electrical Engineering (ICITACEE), pp. 8-13, 2015.

[24] V. Henning and J. Reichelt, "Mendeley-a last. fm for research?," in eScience, 2008. eScience'08. IEEE Fourth International Conference on, pp. 327-328, 2008.

[25] D. Macmillan, "Mendeley: Teaching scholarly communication and collaboration through social networking," in Proceedings of the IATUL Conferences, 2012.

[26] O. C. Robinson, "Sampling in interview-based qualitative research: A theoretical and practical guide," Qual. Res. Psychol., vol. 11(1), pp. 25-41, 2014.

[27] A. Koerber and L. McMichael, "Qualitative sampling methods: A primer for technical communicators," J. Bus. Tech. Commun., vol. 22(4), pp. 454-473, 2008.

[28] A. G. Tuckett, "Applying thematic analysis theory to practice: a researcher's experience," Contemporary nurse : a journal for the Australian nursing profession, vol. 19. pp. 75-87, 2005.

[29] V. Braun and V. Clarke, "Using thematic analysis in psychology," Qual. Res. Psychol., vol. 3 May 2015, pp. 77101,2006

[30] K. Salija, R. Hidayat, and A. A. Patak, "Mendeley impact on scientific writing: Thematic ANAlysis," Int. J. Adv. Sci. Eng. Inf. Technol., vol. 6(5), pp. 657-662, 2016.

[31] M. Thelwall, "Early mendeley readers correlate with later citation counts," Scientometrics, vol. 115(3), pp. 1231-1240, 2018. 
[32] N. Maflahi and M. Thelwall, "When are readership counts as useful as citation counts? Scopus versus Mendeley for LIS journals," J. Assoc. Inf. Sci. Technol., vol. 67(1), pp. 191-199, 2016.

[33] E. Mohammadi, M. Thelwall, S. Haustein, and V. Larivière, "Who reads research articles? An altmetrics analysis of Mendeley user categories," J. Assoc. Inf. Sci. Technol., vol. 66(9), pp. 1832-1846, 2015.

[34] E. Mohammadi and M. Thelwall, "Mendeley readership altmetrics for the social sciences and humanities: Research evaluation and knowledge flows," J. Assoc. Inf. Sci. Technol., vol. 65(8), pp. 1627-1638, 2014.

[35] E. Mohammadi, M. Thelwall, and K. Kousha, "Can Mendeley bookmarks reflect readership? A survey of user motivations," J. Assoc. Inf. Sci. Technol., vol. 67(5), pp. 1198-1209, May 2016.

[36] R. T. Putnam and H. Borko, "What do new views of knowledge and thinking have to say about research on teacher learning?," Educ. Res., vol. 29(1), pp. 4-15, 2000.

\section{BIOGRAPHIES OF AUTHORS}

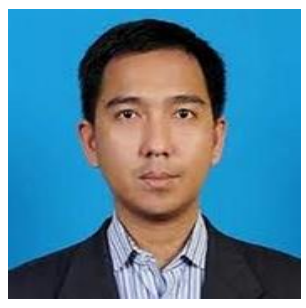

Andi Anto Patak has completed his Ph.D. in Measurement and Evaluation, Faculty of Education, Universiti Teknologi Malaysia (UTM) since 2018. He has been an academic staff since 2007 at the English Department, Faculty of Languages and Literature, Universitas Negeri Makassar, Indonesia. His research interest includes academic writing, writing assessment, educational technology, applied linguistics, and psychology.

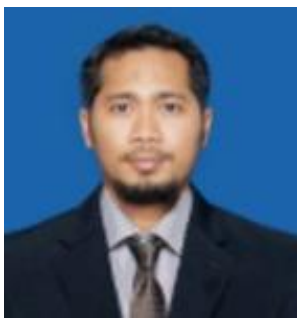

Muhammad Tahir is a senior lecturer in Educational Research, Evaluation, and Assessment. He teaches writing, research in English Language Teaching (ELT), language testing, and seminar in language teaching. His research interest covers educational research, educational evaluation, educational assessment, academic writing, distance education, instructional design, online learning, teacher's performance improvement, and university-community engagement. 